\title{
Motor inhibition from the brainstem is normal in torsion dystonia during REM sleep
}

\author{
D R Fish, D Sawyers, S J M Smith, P J Allen, N M F Murray, C D Marsden
}

\begin{abstract}
The maintenance of axial atonia during REM sleep was monitored in 14 patients with primary torsion dystonia, 10 patients with secondary torsion dystonia, and 10 normal subjects using submental EMG and video EEG telemetry. The excitability of the corticospinal tract during REM sleep was also assessed using scalp magnetic stimulation in seven patients and three controls. During REM sleep dystonic patients had well maintained atonia evidenced by infrequent bursts of submental activity, no episodes of complex semi-purposeful behaviour and reduced motor responses to magnetic stimulation. These findings suggest that the inhibitory centres in the region of the locus coeruleus and their descending pathways to the spinal alpha motor neurons are intact in torsion dystonia.
\end{abstract}

The pathophysiological basis of the motor abnormalities in primary torsion dystonia is unknown. Voluntary movements and muscle stretch produce an overflow of activity to distant muscles, with activation rather than relaxation of antagonists, and spinal reciprocal inhibition is abnormal. ${ }^{1}$ These changes may be due to distortion of descending motor commands to the spinal cord, perhaps as a result of a disturbance of basal ganglia function. However, necropsy neurochemical ${ }^{23}$ and histological ${ }^{45}$ studies in patients with primary torsion dystonia have raised the possibility that pathology in the pontomedullary structures, particularly in the region of the locus coeruleus, may be involved in the pathogenesis of dystonia.

Hornykiewicz et $a l^{2}$ performed detailed necropsy neurochemical studies on the brains of two patients with primary torsion dystonia. There were substantial changes in the noradrenaline, serotonin and dopamine content of several regions of the telencephalon, diencephalon and brainstem. In particular noradrenaline was reduced in the locus coeruleus but elevated in several of its projection areas. Histological examination, however, showed no cell loss in the locus coeruleus itself. The authors speculated that the reduction in noradrenaline was a consequence of decreased noradrenergic input from the adjacent lateral tegmentum. ${ }^{2}$ Subsequently, Jankovic and Svendsen ${ }^{3}$ found necropsy changes in noradrenaline levels in the mid- brain of a patient with idiopathic craniocervical dystonia which they interpreted as a possible consequence of reduced noradrenergic function in the locus coeruleus. Zweig et $\mathrm{al}^{4}$ performed histological studies on the brains of four patients with the clinical diagnosis of primary torsion dystonia. One patient had neurofibrillary tangles and mild neuronal loss in the locus coeruleus, and occasional neurofibrillary tangles in several other brainstem structures. Another patient had prominent cell loss in several brainstem nuclei including the substantia nigra pars compacta, locus coeruleus, raphe nuclei and pedunculopontine nucleus but no abnormalities were found in the other two cases. ${ }^{4}$ Gibb et $a l^{5}$ performed necropsy histological studies on four patients with cranial dystonia. One of these patients had a small pontine angioma, but no abnormalities were found in the other cases. The significance of these histological and neurochemical changes in the brainstem is uncertain. The region of the locus coeruleus appears to be implicated in some, but not all patients with primary torsion dystonia. These abnormalities could represent the primary lesion responsible for the disorder. Alternatively, they could be secondary to undetected abnormalities elsewhere in the brain or the effect of treatment.

Direct study of the brainstem inhibitory systems is not yet possible in conscious human subjects, but REM sleep offers a potential tool with which to investigate the inhibitory pathway that descends from the region of the locus coeruleus to the brainstem and spinal cord. Normal subjects show profound atonia during REM sleep. The physiological basis of this phenomena has been investigated extensively in animals. Supratentorial structures undoubtedly influence REM sleep phenomena ${ }^{6}$ but brainstem structures alone are sufficient for the occurrence of REM atonia. Complete transections of the brainstem at different levels in the cat have shown that stage REM atonia can be produced if the pons and caudal structures are intact. ${ }^{7}$ REM atonia, however, is prevented by bilateral lesions in the region of the locus coeruleus. $^{8-12}$ The neurons involved in this inhibitory process may be situated diffusely within this region. Small bilateral lesions of the cells adjacent to the locus coeruleus (known as the locus coeruleus alpha and peri locus coeruleus alpha) partially inhibit REM atonia. ${ }^{12} \mathrm{~A}$ further restoration of muscle tone during REM sleep may be seen following larger bilateral lesions in this area that involve 
the locus coeruleus itself. ${ }^{10}$ Lack of REM atonia in animals is associated with complex semi-purposeful behaviour during stage REM sleep. ${ }^{1314}$

Similarly, patients with brainstem lesions may have periods of stage REM sleep without atonia, ${ }^{15-18}$ accompanied by "delirious" motor behaviour which may represent the uninhibited acting out of dreams. Cat and rabbit experiments have demonstrated that the descending inhibitory pathway from the region of the locus coeruleus thought to be responsible for REM atonia runs in the lateral tegmentoreticular tract, ${ }^{19}$ and probably excites the cells of the medullary nucleus magnocellularis. ${ }^{20}$ These project to the ventrolateral reticulospinal tract ${ }^{21}$ and ultimately lead to predominantly postsynaptic inhibition of the alpha motor neurons. ${ }^{22}$ Superimposed on the resulting background inhibition during REM sleep alpha motor neurons also receive excitatory inputs which occasionally are of sufficient amplitude to cause membrane depolarisation, and lead to muscle twitches or myoclonic jerks. ${ }^{23}$

This evidence suggests that the atonia of stage REM sleep may be used to study an important descending inhibitory pathway. In this study the hypothesis that torsion dystonia is due to reduced function of the inhibitory pathway descending from the region of the locus coeruleus was investigated by studying motor inhibition during REM sleep in patients with primary and secondary torsion dystonia using submental EMG, video recordings of clinical behaviour and scalp magnetic stimulation.

\section{Subjects and methods}

Three groups were studied: 10 normal subjects (six females and four males, median age 29 years, range 21-64), 14 patients with primary torsion dystonia (eight females, six males, median age 38.5 years, range $15-81$ ) and 10 patients with secondary dystonia (two females, eight males, median age 44.5 years, range 20 74). The clinical details of the patients with torsion dystonia are given in tables 1 and 2 . An additional patient (Case 15) was studied with magnetic stimulation only.

This study was approved by the Medical Ethics Committee of The National Hospitals for Neurology and Neurosurgery. No alterations were made to treatment and all subjects gave informed consent. Sleep studies were performed in a quiet single room after one night of adaptation using the video cable telemetry equipment previously described ${ }^{24}$ and the techniques of Rechtschaffen and Kales. ${ }^{25}$ Subjects retired to bed when they chose, and awoke spontaneously in the morning.

1 The assessment of atonia using submental $E M G$

In normal subjects during stage REM sleep the submental EMG shows a low level of background activity with occasional brief bursts of excitation (fig 1). The number of these bursts were used to assess the maintenance of atonia. All records were coded and scored blind to the diagnosis by two independent observers (DF and DS). Each period of REM sleep was divided into two second mini-epochs and the percentage of these which contained at least one

Table 1 The patients with primary generalised torsion dystonia ${ }^{\star}$

\begin{tabular}{|c|c|c|c|c|c|c|}
\hline $\begin{array}{l}\text { Patient } \\
\text { number }\end{array}$ & $\begin{array}{l}\text { Age } \\
\text { (years) }\end{array}$ & Sex & $\begin{array}{l}\text { Age } \\
\text { onset }\end{array}$ & $F H$ & $D S$ & Drugs (daily dose) \\
\hline $\begin{array}{l}1 \\
2 \\
3 \\
4 \\
5^{\star} \\
6^{\star \dagger} \dagger \\
7 \\
8 \\
9 \\
10 \\
11 \\
12 \\
13 \\
14 \\
15\end{array}$ & $\begin{array}{l}43 \\
22 \\
21 \\
27 \\
39 \\
38 \\
26 \\
27 \\
58 \\
57 \\
46 \\
81 \\
15 \\
72 \\
27\end{array}$ & $\begin{array}{l}M \\
\mathrm{~F} \\
\mathrm{M} \\
\mathrm{F} \\
\mathrm{M} \\
\mathrm{M} \\
\mathrm{F} \\
\mathrm{F} \\
\mathrm{F} \\
\mathrm{F} \\
\mathrm{M} \\
\mathrm{F} \\
\mathrm{M} \\
\mathrm{F} \\
\mathrm{F}\end{array}$ & $\begin{array}{r}8 \\
8 \\
7 \\
5 \\
7 \\
10 \\
10 \\
5 \\
53 \\
51 \\
18 \\
48 \\
5 \\
29 \\
7\end{array}$ & $\begin{array}{l}\mathbf{Y} \\
\mathbf{Y} \\
\mathbf{Y} \\
\mathbf{Y} \\
\mathbf{Y} \\
\mathbf{Y} \\
\mathbf{Y} \\
\mathbf{N} \\
\mathbf{N} \\
\mathbf{N} \\
\mathbf{Y} \\
\mathbf{N} \\
\mathbf{Y} \\
\mathbf{N} \\
\mathbf{Y}\end{array}$ & $\begin{array}{r}3 \\
5 \\
28 \\
18 \\
21 \\
9 \\
11 \\
4 \\
6 \\
8 \\
7 \\
4 \\
26 \\
4 \\
1\end{array}$ & $\begin{array}{l}\text { None } \\
\text { Benzhexol } 90 \mathrm{mg} \\
\text { Diazepam } 5 \mathrm{mg} \text { Benzhexol } 10 \mathrm{mg} \\
\text { Benztropine } 4 \mathrm{mg} \\
\text { Diazepam } 30 \mathrm{mg} \\
\text { Primidone } 750 \mathrm{mg} \text { Valproate } 1 \mathrm{~g} \\
\text { None } \\
\text { None } \\
\text { Benzhexol } 8 \mathrm{mg} \text { Dexamphetamine } 10 \mathrm{mg} \\
\text { Benzhexol } 35 \mathrm{mg} \text { Propanolol } 180 \mathrm{mg} \\
\text { Benzhexol } 6 \mathrm{mg} \\
\text { Benzhexol } 3 \mathrm{mg} \\
\text { Benzhexol } 20 \mathrm{mg} \text { Pimozide } 30 \mathrm{mg} \text { Diazepam } 16 \mathrm{mg} \\
\text { None } \\
\text { Benzhexol } 45 \mathrm{mg}\end{array}$ \\
\hline
\end{tabular}

*Ashkenazy Jew.

+ Patient had previous thalamotomy.

DS $=$ Disability score $(0-30)$ on Fahn and Marsden Scale. ${ }^{32} . \mathbf{F H}=$ Family history of dystonia

Table 2 The patients with secondary torsion dystonia

\begin{tabular}{llllllll}
\hline $\begin{array}{l}\text { Patient } \\
\text { number }\end{array}$ & Sex & Age & $\begin{array}{l}\text { Relevant } \\
\text { clinical } \\
\text { details }\end{array}$ & $\begin{array}{l}\text { Age } \\
\text { onset } \\
\text { (years) }\end{array}$ & Sites & DS & Drugs (daily dose) \\
\hline 16 & M & 20 & Enceph & 9 & Gen & 21 & Benztropine 2 mg Diazepam 10 mg \\
$17 \dagger$ & M & 30 & Birth injury & 4 & Gen & 29 & Haloperidol 3 mg Diazepam 15 mg \\
18 & F & 40 & Birth injury & 13 & Gen & 6 & Clonidine 150 ug Benzhexol 6 mg \\
19 & F & 61 & Drugs & 56 & Cranial & 11 & Benzhexol 6 mg \\
20 & M & 43 & Enceph & 2 & Gen & 20 & None \\
21 & M & 52 & CVA & 46 & Trunk & 1 & Sulpiride 600 mg Diazepam 10 mg \\
22 & M & 74 & Enceph & 31 & Gen & 14 & Benzhexol 4 mg \\
23 & M & 46 & Pyramidal signs & 37 & Legs & 4 & Madopar 975 mg \\
24 & M & 67 & Rapid disease progress 38 & Gen & 16 & Diazepam 6 mg Orphenadrine 150 mg \\
25 & M & 48 & Rapid disease progress 42 & Gen & 8 & None \\
\hline
\end{tabular}

Enceph $=$ Encephalitis. Gen $=$ Generalised. $\dagger=$ Thalamotomy

DS = Disability score (0-30) on Fahn and Marsden Scale ${ }^{32}$

$\star$ Reproduced from reference 31, copyright 1990, American Medical Association. 
Figure 1 REM sleep showing a brief burst of submentalis EMG activity in a normal subject surface $E M G, E O G=$ electro-oculogram). (subment $=$ submentalis

$25 \mathrm{uV}$

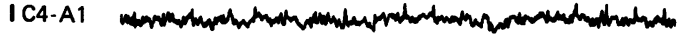
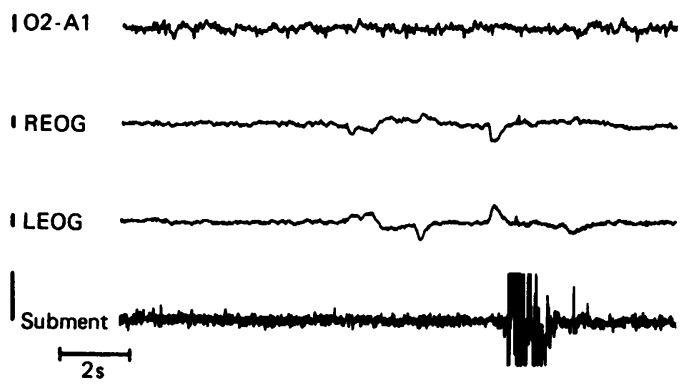

burst of submentalis activity that was more than $50 \%$ above the baseline was then determined. The interobserver correlation coefficient for this measurement was $\mathbf{0 . 8 2}$ (linear regression), and the mean of the two scores was used (fig 2).

\section{Clinical behaviour}

Overnight video monitoring was performed using a low light sensitivity camera. The entire recording was reviewed by one of us (DF) to assess the clinical behaviour.

\section{Scalp magnetic stimulation}

The effect of stage REM sleep on the amplitude and latency of the response of abductor digiti minimi (ADM) to scalp magnetic stimulation was subsequently studied in seven patients with primary torsion dystonia (Cases $1-3,5,7$, 8 and 15) and three control subjects. Data on one control (Case 3) was obtained from two separate nights. Sleep was monitored using the above techniques, except for the EEG which was recorded directly on to paper. Scalp magnetic stimulation employing an anticlockwise current with the coil centred over the vertex was performed using methods previously described. ${ }^{26}$ Between stimuli the coil rested on the head because preliminary studies had shown that this reduced the tendency for stimuli to awaken the subject. The magnitude of stimulation was $25 \%$ above the relaxed threshold. The activity of the right ADM was monitored using surface EMG. The baseline to peak amplitude, and the latency to onset of each ADM response were measured. Baseline levels of these parameters were determined for each subject using four stimuli before and after the overnight sleep with the subjects as relaxed as

Figure 2 The percentage of $2 s$ miniepochs during stage REM sleep containing at least one burst of submentalis (SM) EMG activity, expressed as the mean of the two observers.

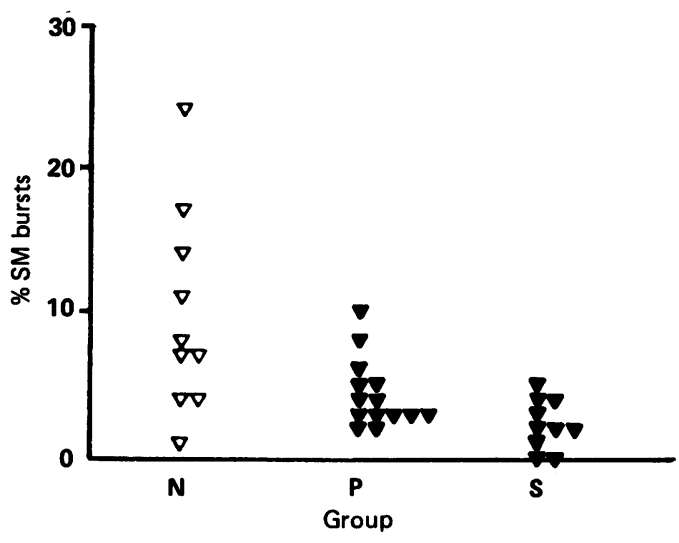

possible. Relaxation was checked using the audio channel of the ADM surface EMG. The number of stimuli given to each subject during REM sleep was determined by the amount of this sleep stage and the posture of the subject. No stimuli were given during muscle twitches. The interval between stimuli was at least 20 seconds. The amplitudes of the responses during REM sleep were expressed as a percentage of the median awake value. The absolute latency of the ADM response was measured; this includes not only the time for conduction from motor cortex to spinal cord, but also a large peripheral component. Cervical stimulation, which would allow computation of the central conduction time, was only performed in one subject (Case 3 ) during wakefulness, but could not be done during sleep because of the need for patient cooperation. The change therefore in total ADM latency for each response obtained during REM sleep was defined as the latency of the REM response-median awake latency.

\section{Results}

1 The frequency of bursts of submentalis activity during REM sleep

All control subjects and patients showed a reduced background level of submental EMG activity during REM sleep compared with wakefulness. The group of patients with secondary torsion dystonia had fewer bursts of submentalis activity than the group of normal subjects ( $p<0.01$ Mann Whitney, two tailed, fig 2). The results for the group of patients with primary torsion dystonia were similar to the control group ( $p=0.07$ Mann Whitney, two tailed, fig 2).

\section{Clinical behaviour}

Review of the overnight video recordings documented that no episodes of complex semipurposeful or delirious behaviour occurred during REM sleep in either patients or controls.

3 The effect of stage REM sleep on the response to scalp magnetic stimulation

Four patients with torsion dystonia yielded information (Cases 1, 3, 8 and 15). One other patient was awoken from her only period of REM sleep by the first stimulus (which did not produce a detectable response in ADM), and two other patients had no stage REM sleep under these recording circumstances. The recording gains were adjusted during the night to try and detect small responses. However, responses below about $2 \%$ of the wake level were unlikely to be detected. The normal subjects received a total of 92 stimuli. Sixty five of these stimuli produced a detectable response in $\mathrm{ADM}$. Cases 1, 3, 8 and 15 with primary torsion dystonia received a total of 81 stimuli during stage REM sleep. Sixty of these produced a detectable response in ADM. Although there was substantial intra and inter subject variability in both controls and patients, most responses during REM sleep were of small amplitude and prolonged latency 
Table 3 The effect of stage REM sleep on the amplitude and latency of ADM EMG responses to scalp magnetic stimulation in A) normal subjects and B) patients with primary dystonia. The amplitudes are expressed as a percentage of the wake baseline. The change in latency is defined as the latency from stimulation to the onset of response- the wake baseline latency

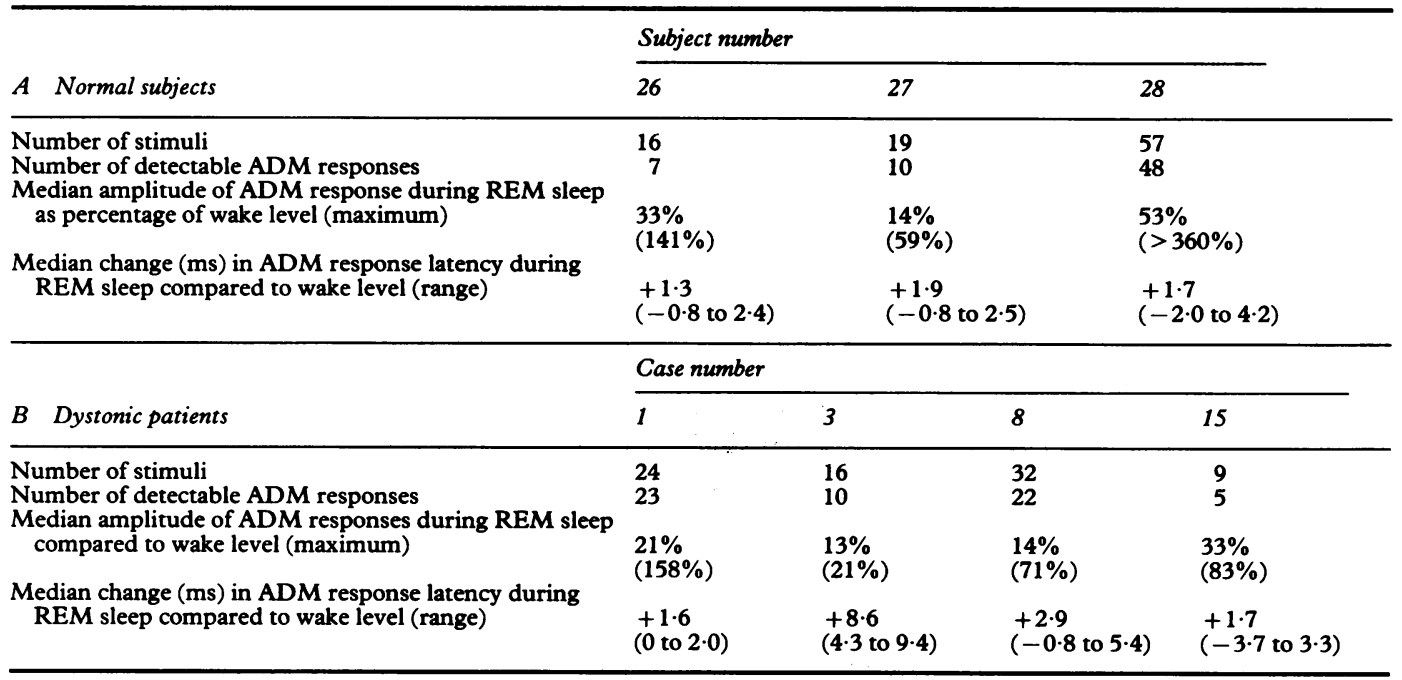

compared to wakefulness (table 3). Case 3 consistently showed particularly small and delayed responses during REM sleep (fig 3).

\section{Discussion}

The three methods used to assess atonia (submental EMG, video recording of the clinical behaviour and scalp magnetic stimulation) demonstrated unequivocally that motor inhibition is well maintained during REM sleep in patients with torsion dystonia.

Patients with torsion dystonia did not show more bursts of increased submental activity

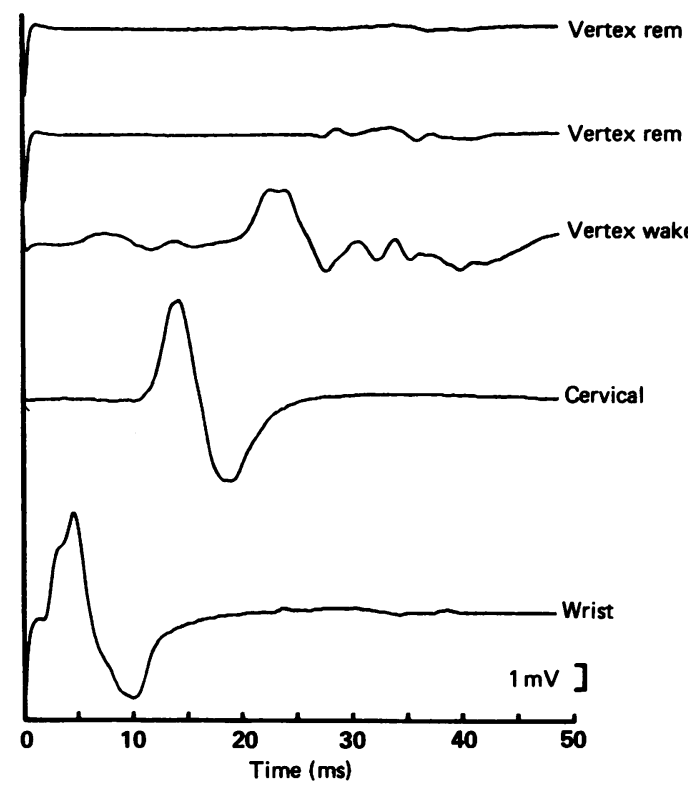

Figure 3 EMG responses of the right ADM to central magnetic stimulation given at the beginning of each sweep, during wake and stage REM sleep in Case 3 with primary torsion dystonia. The top two traces show the response to stimulation with the coil centred over the vertex, current anticlockwise, at a strength of $25 \%$ above threshold, during REM sleep. The third trace shows the response to similar stimulation during wakefulness. The fourth and fifth traces show the response of ADM to electrical stimulation at the cervical level and wrist respectively. The ADM responses during REM sleep were much smaller than in wakefulness and delayed in this case by about $8 \mathrm{~ms}$. during REM sleep than normal subjects. Indeed these were significantly reduced in the secondary group. This finding is in agreement with the observation of Wein and Golubev ${ }^{27}$ that patients with torsion dystonia have reduced numbers of gross body movements during sleep. Similarly EMG recordings have shown reduced numbers of gross body movements and muscle twitches during both nonREM and REM sleep in children with hereditary DOPA responsive dystonia showing marked diurnal variation; ${ }^{28}$ interestingly, in the latter condition these were restored by treatment with levodopa.

No episodes of complex semi-purposeful or delirious behaviour occurred during stage REM sleep. This is in contrast to the activity seen during REM sleep in cats with pontomedullary lesions in the region of the locus coeruleus, ${ }^{10114}$ and the delirious behaviour observed in some patients with structural or degenerative lesions involving this region..$^{15-18}$

In another study on the same group of patients with torsion dystonia Fish et al ${ }^{29}$ have reported that the dystonic movements occurred only rarely during sleep, and were usually associated with arousals or lightenings of sleep. This was similar to the dyskinetic movements of Parkinson's disease, Huntington's Chorea and Gilles de la Tourette syndrome. This would be in favour of maintained descending inhibition during sleep, but could also be explained by a direct effect of sleep on the cerebral generators of these movements.

There was marked variability of response amplitudes of ADM to central magnetic stimulation during REM sleep in both the normal subjects and patients with dystonia. This may reflect the rapid fluctuations in alpha motor neuron excitability that are known to occur in REM sleep. ${ }^{23}$ Occasional responses were seen above the wake levels in normal subjects and once in patients with dystonia. They were less frequent than in the previous study of Hess et al. ${ }^{26}$ This difference may have arisen because of the avoidance of stimulation during muscle twitches and the use of more 
stimuli in this study. Nevertheless, motor inhibition during REM sleep in patients with primary torsion dystonia was confirmed by the small amplitude and prolonged latencies of responses of $\mathrm{ADM}$ to scalp magnetic stimulation in this sleep stage compared with wakefulness. A high level of spinal inhibition would, by increasing the number of descending volleys necessary for depolarisation of the spinal motor neuron, tend to increase the latency of responses. The present findings therefore support the report of marked inhibition of $\mathrm{H}$ reflexes, indicating spinal inhibition, during stage REM in two patients with secondary dystonia. ${ }^{30}$ The consistently very prolonged latency of ADM responses during REM compared with wakefulness that occurred in one patient (Case 3) with severe torsion dystonia during REM sleep is unexplained, but the possibility of some facilitation during wakefulness is recognised.

Presumably REM atonia is mediated by the same structures and pathways in both normal subjects and patients with torsion dystonia. This study does not exclude the possibility that torsion dystonia could be due to selective brainstem lesions, but does suggest that the inhibitory centres in the region of the locus coeruleus and their descending pathway to the alpha motor neurons are intact.

1 Rothwell JC, Day BL, Obeso JA, Beradell A, Marsden CD Reciprocal inhibition between muscles of the human forearm in normal subjects and patients with idiopathic torsion dystonia. In: Fahn S, Marsden CD, Calne DB,
eds. Dystonia 2. Advances in Neurology, 1988;50:133-40. eds. Dystonia 2. Advances in Neurology, 1988;50:133-40.
2 Hornykiewicz O, Kish SJ, Becker LE, Farley I, Shannak K. Brain neurotransmitters in dystonia musculorum deformans. N Engl J Med 1986;315:347-53.

3 Jankovic J, Svendsen ON. Brain neurotransmitters in dystonia. N Engl J Med 1987;316:278-9.

4 Zweig RM, Hedreen JC, Jankel WR, Casanova MF, Whitehouse PJ, Price DL. Pathology in brainstem regions of individuals with primary torsion dystonia. Neurology 1988;38:702-6.

5 Gibb WRG, Lees AJ, Marsden CD. Pathological report of four patients presenting with cranial dystonia. Movement four patients presenting

6 Jouvet $M$. The regulation of paradoxical sleep by the hypothalamo-hypophysis. Arch. Ital Biol 1988;126: hypothalan

7 Jouvet M. Recherches sur les structures nerveuses et les mecanismes responsables des differentes phases du sommeil physiologique. Arch Ital Biol 1962;100:125-206.

8 Jouvet M, Delorme F. Locus coereleus et sommei paradoxal. CR Soc Biol 1965;159:895-9.

9 Sastre JP, Sakai K, Jouvet M. Bilateral lesions of the dorsolateral pontine tegmentum II. Effect upon muscle atonia. Sleep Res 1978;7:44.

10 Hendricks JC, Morrison AR, Mann GL. Different behaviours during paradoxical sleep without atonia depend upon pontine lesion sites. Brain Res 1982;239: 81-105.

11 Siegel-JM, Nienhuis R, Tomaszewski KS. Rostral brainstem contributes to medullary inhibition of muscle tone. Brain Res 1983;268:344-8.

12 Sakai K, Sastre JP, Kanamoni N, Jouvet M. State specific neurons in the pontomedullary reticular formation with special reference to the postural atonia during paradoxical sleep in the cat. In: Pompeiano O, Ajmone-Marsan C, eds. Brain mechanisms and perceptual awareness. New York: Raven Press, 1981:405-29.

13 Sastre JP, Jouvet M. Le comportment onirique du chat. Physiology and Behaviour 1979;22:979-89.

14 Morrison AR, Reiner PB. A dissection of paradoxical sleep. In: McGinty DJ, Drucker-Colin R, Morrison A, et al, eds. Brain mechanisms of sleep. New York: Raven Press, 1985:97-110.

15 Barros-Ferreira M, Chodkiewicz J, Lairy G, Salzaru P. Disorganised relations of tonic and phasic events of REM Disorganised relations of tonic and phasic events of REM sleep in a case of brainstem

16 Isono G, Ishii K, Shibata Y, Hoshi T. REM sleep without atonia in a case of bilateral acoustic neuroma. Seishin Igaku (Tokyo) 1979;21:1221-8.

17 Schenck CH, Bundlie SR, Patterson AL, Mahowald MW Rapid eye movement sleep behaviour disorder. JAMA 1987;257:1786-9.

18 Salva MAQ, Guilleminault C. Olivopontocerebellar degeneration and REM sleep without atonia. Neurology 1986;36:576-8.

19 Webster HH, Friedman L, Jones BE. Modification of paradoxical sleep following transection of the reticular paradoxical sleep following transection of the reticular
formation at the pontomedullary junction. Sleep 1986;9: $1-23$.

20 Kanamoni N, Sakai K, Jouvet $M$. Neuronal activity specific to paradoxical sleep in the ventromedial medullary forma tion of unrestrained cats. Brain Res 1980;189:251-5.

21 Jankowska E, Lund S, Lundberg A, Pompeiano $O$ Inhibitory effects evoked through ventral reticulospinal pathways. Arch Ital Biol 1968;105:124-40.

22 Morales FR, Chase MH. Postsynaptic mechanisms responsible for motor inhibition during active sleep. In: Chase MH, Weitzman E, eds. Sleep disorders: basic and clinical research. New York: Spectrum, 1983:71-93.

23 Chase MH, Morales FR. Subthreshold excitatory activity and motor neurone discharge during REM periods of active sleep. Science 1983;22:1195-8.

24 Roberts R, Fitch P. Monitoring at the National Hospital Queen Square, London. Electroenceph Clin Neurophysiol Queen Square, Lond

25 Rechtschaffen A, Kales A, eds. A manual of standardised terminology and scoring system for sleep stages in human subjects. Washington: US Government Printing Office, 1968.

26 Hess CW, Mills KR, Murray NMF, Schriefer T. Magnetic stimulation of the human brain during natural sleep. Neurosci Lett 1987;82:47-52.

27 Wein A, Golubev V. Polygraphic analysis of sleep in dystonia musculorum deformans. Waking Sleeping 1979;3:41-50.

28 Segawa M, Hosaka A, Miyagawa F, Nomura Y, Imai H. Hereditary progressive dystonia with marked diurnal fluctuation. Adv Neurol 1976;14:215-33.

29 Fish DR, Sawyers D, Allen PJ, Blackie JD, Lees A, Marsden $\mathrm{CD}$. The effect of sleep on the dyskinetic movements of Parkinson's Disease, Huntington's Chorea, torsion dysParkinson's Disease, Huntington's Chorea, torsion dystonia and Gilles
1990 (in Press).

30 Mano T, Shiozawa Z, Sobue I. Extrapyramidal involuntary movements during sleep. Electroencaeph Clin Neurophysiol 1982;35S:431-41.

31 Fish DR, Allen PJ, Sawyers D, Marsden CD. Sleep spindle in torsion dystonia. Arch Neurol 1990;47:216-18.

32 Burke E, Fahn S, Marsden CD, Bressman S, Moskowitz C Friedman J. Validity and reliability of a rating scale for the primary torsion dystonia. Neurology 1985;35:73-7. 